Acta Sci. Pol. Technol. Aliment. 20(2) 2021, 237-245

pISSN 1644-0730

eISSN 1898-9594

http://dx.doi.org/10.17306/J.AFS.2021.0902

ORIGINAL PAPER

Received: 27.10 .2020

Accepted: 12.04 .2021

\title{
PRODUCTION OF PROBIOTIC WORT-BASED BEVERAGES WITH GRAPEFRUIT (CITRUS PARADISI L.) OR TANGERINE (CITRUS RETICULATA L.) ZEST ESSENTIAL OIL ADDITION
}

\author{
Teodora Tomova ${ }^{1}$, Ivan Petelkov², Vesela Shopska ${ }^{2 \times}$, Rositsa Denkova-Kostova ${ }^{3}$, \\ Georgi Kostov², Zapryana Denkova ${ }^{1}$
}

${ }^{1}$ Department Microbiology, Technological Faculty, University of Food Technologies - Plovdiv

Maritza 26, 4000 Plovdiv, Bulgaria

2Department Technology of Wine and Beer, Technological Faculty, University of Food Technologies - Plovdiv Maritza 26, 4000 Plovdiv, Bulgaria

${ }^{3}$ Department Biochemistry and Molecular Biology, Technological Faculty, University of Food Technologies - Plovdiv

Maritza 26, 4000 Plovdiv, Bulgaria

\begin{abstract}
Background. In recent years, increasing health awareness in consumers has motivated breweries to expand their beverage ranges with products with increased biological value. The aim of the present research was to develop probiotic wort-based beverages with grapefruit or tangerine zest essential oil addition.

Materials and methods. Wort was produced with $60 \%$ Pilsen malt, 20\% Vienna malt and 20\% Caramel Munich II malt with and without the addition of $0.05 \%(\mathrm{v} / \mathrm{v})$ grapefruit or tangerine essential oils. It was inoculated with the probiotic yeast strain Saccharomyces cerevisiae var. boulardii Y1. Fermentations were carried out at a constant temperature of $10^{\circ} \mathrm{C}$ for 5 days. The dynamics of the extract, the alcohol content and the concentration of viable cells were monitored daily. The total phenolic content, phenolic acid and flavonoid phenolic compounds were determined because of their antioxidant activity. The antioxidant activity was determined by radical scavenging assay (DPPH) and ferric reducing antioxidant power (FRAP). A descriptive organoleptic evaluation of the final beverages was performed.

Results. The essential oils inhibited yeast growth to some extent at the beginning of the fermentation, even at a concentration of $0.05 \%(\mathrm{v} / \mathrm{v})$, which resulted in lower alcohol content in the beverages with essential oil addition. Nevertheless, at the end of fermentation the concentration of viable cells was almost equal in all the beverages. Tangerine essential oil addition led to the highest content of phenolics, of which phenolic acids predominated. Therefore, the highest antioxidant activity of the beverage with tangerine essential oil can be ascribed to phenolic acids. The results of the sensorial evaluation also showed that the panel had preference towards the beverage with tangerine essential oil.

Conclusion. The combination of essential oil and the probiotic yeast strain resulted in beverages with higher biological value than the beverages produced with the probiotic strain alone. The results obtained will be used for optimisation of process variables in the production of pilot-scale wort-based probiotic beverages with essential oil addition.
\end{abstract}

Keywords: wort, probiotic yeast, essential oil, fermentation dynamics, antioxidant activity

\footnotetext{
This work were supported by the Bulgarian Ministry of Education and Science under the National Research Programme "Healthy Foods for a Strong Bio-Economy and Quality of Life” approved by DCM \# 577/17.08.2018.
}

『vesi_nevelinova@abv.bg 


\section{INTRODUCTION}

Functional foods contain technologically developed ingredients with a specific health benefit (Niva, 2007). Beverages can be described as functional if they do not contain more than $1.2 \% \mathrm{v} / \mathrm{v}$ ethanol (Regulation..., 2006). The positive effects of a functional food can be either maintaining a state of well-being and health or reducing the risk of development of pathological consequences. Among the most promising targets for functional food science are gastrointestinal functions, redox and antioxidant systems, and metabolism of macronutrients (Roberfroid, 2000). In these areas, sweet wort, probiotic yeast Saccharomyces cerevisiae var. boullardii and different essential oils can be used as ingredients for the development of functional beverages.

Sweet wort is produced after a mixture of ground malt is mashed with a carefully controlled amount of water and subsequent filtration of this mash. Sweet wort consists of many substances that are beneficial for human health such as: fibres ( $\beta$-glucan and arabinoxylan), antioxidants (phenolic compounds and melanoidins), and vitamins (folate, riboflavin, pantothenic acid, pyridoxine and niacin) (Bamforth, 2004; Briggs et al., 2004; Zhao, 2014).

$S$. boulardii is the only yeast species with probiotic properties. Recently, many clinical studies have shown its beneficial effects against acute diarrhea in children by significantly reducing the duration of the disease. On the other hand, it is also efficient in the prevention and treatment of antibiotic-associated diarrhea and in traveler's diarrhea with a significant efficacy. S. boulardii also helps in the treatment of Clostridium difficile and Escherichia coli infections, reducing the occurrence of diarrhea and colitis (colon inflammation). S. boulardii produces enzymes in the digestive tract (aminopeptidase, phosphatase) that widely inhibit some toxins produced by pathogenic microorganisms. S. boulardii has been used successfully in the production of alcohol-free beer (Czerucka et al., 2000; Senkarcinova, 2019).

Essential oils are used in a wide variety of consumer goods such as confectionery food products, soft drinks, and distilled alcoholic beverages. In addition to their widespread use as a flavoring material they are used in the nutritional and agricultural fields for their reported antibacterial, antifungal, antiviral, nematicidal, insecticidal, and antioxidant properties (Turek, and Stintzing, 2013).

Grapefruit (Citrus paradisii) essential oil possesses antioxidant, antiseptic, disinfectant (due to antiviral and antimicrobial activities), diuretic, and stimulant properties (Ng et al., 2016).

Tangerine (Citrus reticulata L. var.) essential oil can help relieve stress and digestive problems but is mostly used to increase circulation to the skin, reducing fluid retention and to prevent the appearance of stretch marks. Tangerine oil is soothing to the nervous system and has a tonic effect on the digestive system, while helping flatulence, diarrhea and constipation. This essential oil exhibits antibacterial, antifungal and antioxidant properties (Fayed, 2009; Mandal and Mandal, 2016).

The aim of this study was to evaluate the effects of the addition of grapefruit and tangerine essential oils on the dynamics of wort fermentation with a probiotic $S$. boulardii strain. The phenolic compounds content and the antioxidant activity of the beverages produced were examined. The sensorial characteristics of the produced functional beverages were also described.

\section{MATERIALS AND METHODS}

\section{Essential oils}

Tangerine (Citrus reticulata L.) and grapefruit (Citrus paradisi L.) zest essential oils were used. The tangerine and grapefruit essential oils were obtained from the dried zest of $C$. reticulata $\mathrm{L}$. $(0.0167 \mathrm{~g} \mathrm{EO} / \mathrm{g} \mathrm{DW})$ and C. paradisi L. (0.0158 g EO/g DW). $250 \mathrm{~g}$ from each plant material was ground and passed through a $0.5 \mathrm{~mm}$ sieve. The moisture content analyzed by AOAC 934.06 (AOAC, 2007) was established to be $1.7 \%$ for tangerine and $1.9 \%$ for grapefruit. The essential oils were extracted by aqueous distillation in a laboratory glass apparatus according to the British Pharmacopoeia, modified by Balinova and Diakov (1974). The ground plant material was processed using the following parameters: plant material:water ratio $=1: 20$; plant material:flask volume ratio $=1: 100$, frequency of $6 \%$ and duration of $300 \mathrm{~min}$. The distillation rate was maintained evenly at the beginning of the process for 5 or 10 minutes and in the middle and at the end of the process the quantity of the obtained essential oil and the distillation water were recorded 
every 20-30 minutes. The end of the distillation was determined when two consecutive measurements did not show an increase in the essential oil amount. The experiments were performed in triplicate.

\section{Microorganisms}

Wort fermentation was carried out using the probiotic yeast strain Saccharomyces cerevisiae var. boulardii $\mathrm{Y} 1$, which was isolated from spontaneously fermented oat milk.

\section{Media}

Wort agar was supplied by Merck, Germany.

\section{Reagents}

Folin-Ciocalteu reagent, gallic acid, caffeic acid, quercetin, DPPH (2,2-diphenyl-1-picrylhydrazyl), TPTZ (2,4,6-tripyridyl-s-triazine), $\mathrm{FeCl}_{3} \cdot 6 \mathrm{H}_{2} \mathrm{O}$, and Trolox (6-hydroxy-2,5,7,8-tetramethylchromane-2-carboxylic acid) were purchased by Sigma-Aldrich. Hydrochloric acid was purchased by Merck (Germany). All the other reagents were of analytical grade.

\section{Wort preparation}

Wort was produced with $60 \%$ Pilsen malt, $20 \%$ Vienna malt and 20\% Caramel Munich II malt, which was purchased from Bestmaltz (Germany). The malt was milled using a hand disc mill (Corona, Germany). The wort was produced in a $20 \mathrm{~L}$ laboratory scale brewery (Braumeister, Germany). $4.5 \mathrm{~kg}$ of malt was mixed with water at a ratio of 1:5. Mashing was conducted by increasing the temperature by $1{ }^{\circ} \mathrm{C} / \mathrm{min}$ and by maintaining rests at the following temperatures: 30 min at $50^{\circ} \mathrm{C}$ and $60 \mathrm{~min}$ at $77^{\circ} \mathrm{C}$. Lautering and boiling were also conducted in the same Braumeister. Boiling duration was approximately $1 \mathrm{~h}$ without hop addition. After hot trub removal, the wort was cooled to the fermentation temperature. The wort extract was $12.4 \%$ $(\mathrm{w} / \mathrm{w})$ and the $\mathrm{pH}$ was 5.30 .

\section{Wort fermentation}

The wort obtained was divided into three equal parts. $0.05 \%(\mathrm{v} / \mathrm{v})$ of grapefruit and tangerine essential oils was added to the first and second part, respectively, and the third part was used as a reference sample. The fermentations were carried in plastic bottles with a volume of $300 \mathrm{~cm}^{3}$ and equipped with an airlock system. $200 \mathrm{~cm}^{3}$ of wort was placed into bottles and inoculated with a $2 \mathrm{ml} \mathrm{(1 \%} \mathrm{inoculum)} \mathrm{yeast} \mathrm{suspen-}$ sion with an initial concentration of $2.10^{9} \mathrm{CFU} / \mathrm{cm}^{3}$. The bottles were incubated at a constant fermentation temperature of $10^{\circ} \mathrm{C}$ for 5 days.

\section{Analytical methods and procedures}

Fermentation parameters. Original and apparent extract (methods 8.2.1, 8.3, 9.4), ethanol (method 9.2.1) and degree of fermentation (method 9.5) were measured according to EBC standard methods (Analytica, 2004).

Determination of the number of viable yeast cells spread plate method on malt-agar medium. Appropriate tenfold dilutions of the samples were prepared using a sterile saline solution. $0.1 \mathrm{~cm}^{3}$ of the last three dilutions was used to spread plating in the Petri dishes on a malt-agar medium. The inoculated Petri dishes were incubated for 24 hours at $30 \pm 1{ }^{\circ} \mathrm{C}$ until the appearance of countable single yeast colonies. The number of single colonies was used to estimate the concentration of viable yeast cells in the sample.

Phenolic content. The wort was diluted at a ratio of 1:10 with methanol, rested for 30 minutes and filtered using Whattman no. 1 filter paper. The filtrate was used to analyze the phenolic compounds and the antioxidant activity of the wort.

The content of total phenolic compounds was determined using the Folin-Ciocalteu (FC) method, as described by Dvořáková et al. (2008) with slight modifications. $1 \mathrm{~cm}^{3}$ of sample, $4 \mathrm{~cm}^{3}$ of FC working solution, and $5 \mathrm{~cm}^{3}$ of sodium carbonate $(7.5 \% \mathrm{w} / \mathrm{v})$ were introduced into a test tube. This solution was agitated and rested for $1 \mathrm{~h}$. The absorbance was determined at $765 \mathrm{~nm}$ in a Shimadzu UV-VIS 1800 spectrophotometer (Kyoto, Japan) against a blank sample prepared with purified water. The calibration curve was performed with gallic acid, and the results were expressed as $\mathrm{mg}$ of gallic acid equivalents $-\mathrm{GAE} / \mathrm{dm}^{3}$.

The total phenolic compounds, total phenolic acids and total flavonols were determined using the modified Glories method as described by Mazza et al. (1999). Briefly, the sample $\left(1 \mathrm{~cm}^{3}\right)$ was pipetted into a test tube and $1 \mathrm{~cm}^{3} 0.1 \% \mathrm{HCl}$ in $95 \%$ ethanol (v/v) and $18.2 \mathrm{~cm}^{3} 2 \% \mathrm{HCl}(\mathrm{v} / \mathrm{v})$ were added. The solution 
was thoroughly mixed and rested for approximately 15 min before the absorbance was read with a spectrophotometer against a blank sample prepared with purified water. The absorbance $(A)$ at $280 \mathrm{~nm}$ was used to estimate the total phenolic content, $A 320 \mathrm{~nm}$ was used to estimate the phenolic acids, and $A 360 \mathrm{~nm}$ was used to estimate flavonols. The calibration curves for the total phenolic compounds, total phenolic acids and total flavonols were constructed by using gallic acid, caffeic acid and quercetin, respectively, as a standard.

Antioxidant activity. The antioxidant activity was measured using the DPPH method as described by Dinkova et al. (2014) with minor modifications. Briefly, $0.25 \mathrm{~cm}^{3}$ of sample was added to a $2.25 \mathrm{~cm}^{3} \mathrm{DPPH}$ solution in methanol $\left(6 \times 10^{-5} \mathrm{M}\right)$; the mixture was left for $15 \mathrm{~min}$ (kept in the dark at room temperature) so that a reaction could take place, and then the absorbance was measured at $517 \mathrm{~nm}$ against a blank sample with purified water. The control sample was made with methanol.

The FRAP assay was done according to Benzie and Strain (1996) with some modifications. The stock solutions included $300 \mathrm{mM}$ acetate buffer $(3.1 \mathrm{~g}$ $\mathrm{C}_{2} \mathrm{H}_{3} \mathrm{NaO}_{2} \cdot 3 \mathrm{H}_{2} \mathrm{O}$ and $\left.16 \mathrm{~cm}^{3} \mathrm{C}_{2} \mathrm{H}_{4} \mathrm{O}_{2}\right), \mathrm{pH} 3.6,10 \mathrm{mM}$ TPTZ solution in $40 \mathrm{mM} \mathrm{HCl}$, and $20 \mathrm{mM} \mathrm{FeCl}_{3} \cdot 6 \mathrm{H}_{2} \mathrm{O}$ solution. The fresh working solution was prepared by mixing acetate buffer, TPTZ solution and $\mathrm{FeCl}_{3} \cdot 6 \mathrm{H}_{2} \mathrm{O}$ solution at a ratio of $10: 1: 1$. The extracts $\left(0.15 \mathrm{~cm}^{3}\right)$ were allowed to react with $2.85 \mathrm{~cm}^{3}$ of the FRAP solution for $4 \mathrm{~min}$ in the dark. Readings of the coloured product were then taken at $593 \mathrm{~nm}$ against a blank sample prepared with methanol.

For both analyses of the antioxidant activity, the results were determined from a calibration curve using Trolox as a standard and the results were expressed as $\mu \mathrm{mol}$ Trolox equivalents $/ \mathrm{dm}^{3}$.

\section{Sensory analysis}

A sensory evaluation of the beverages was carried out by a trained, 6-member tasting panel. The samples were evaluated for aroma and flavor using descriptive method (methods 13.10 and 13.3) (Analytica EBC, 2004).

\section{Statistical analysis}

The results of all the analyses were expressed as the mean values \pm standard deviation of three replicates using Microsoft Excel 2013. Multiple comparisons for verification of statistical differences in the groups were performed using the Fisher's least significant difference (LSD) method using the Statgraphics Centurion 19 Trial version.

\section{RESULTS AND DISCUSSION}

\section{Fermentation dynamics}

In our preliminary studies, the antimicrobial activity of grapefruit and tangerine essential oils against $S$. boulardii was investigated using the disc-diffusion method. It was found that they did not show antimicrobial activity against the tested microorganism in concentrations up to $1 \%(\mathrm{v} / \mathrm{v})$ (unpublished data). Because of the oils' strong taste and aroma, it was decided that they should be used in concentrations of $0.05 \%(\mathrm{v} / \mathrm{v})$. For functional beverage production, sweet wort with an optimized biological profile and low content of fermentable sugars (about $30 \%$ of wort extract) was used. The reduction of the alcohol content was achieved simultaneously using the low final attenuation of wort and a low fermentation temperature at $10^{\circ} \mathrm{C}$, which was lower than the $S$. boulardii optimal growth temperature $\left(37^{\circ} \mathrm{C}\right)$ (Czerucka et al., 2007).

The results for fermentation dynamics are shown in Figure 1. The fermentation started relatively slowly (after 48 hours) because of the combination of a low fermentation temperature and a low content of fermentable sugars (Figs. 1a and 1b). Moreover, the essential oils inhibited yeast growth to some extent, even at a concentration of $0.05 \%(\mathrm{v} / \mathrm{v})($ Fig. 1c). This

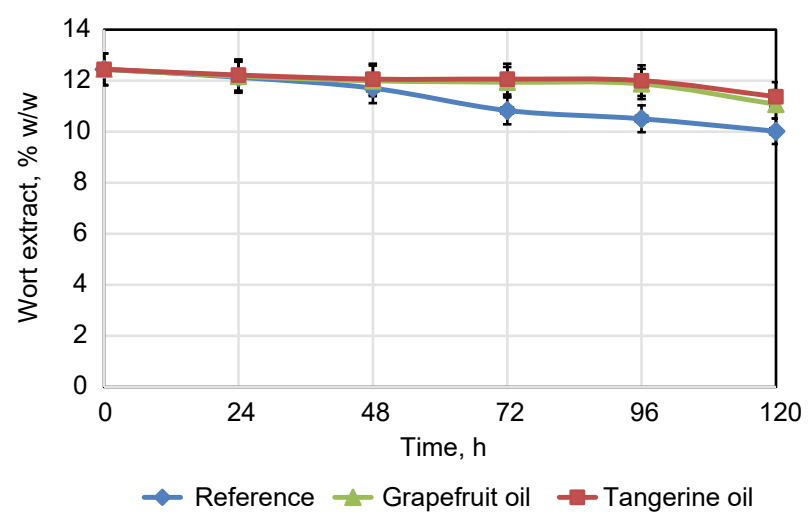

Fig. 1a. Changes in wort extract during fermentations 


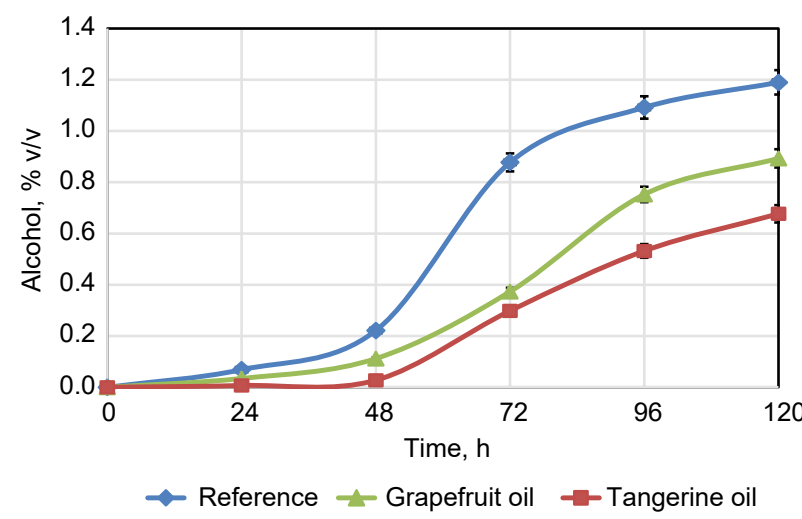

Fig. 1b. Changes in alcohol content during fermentations

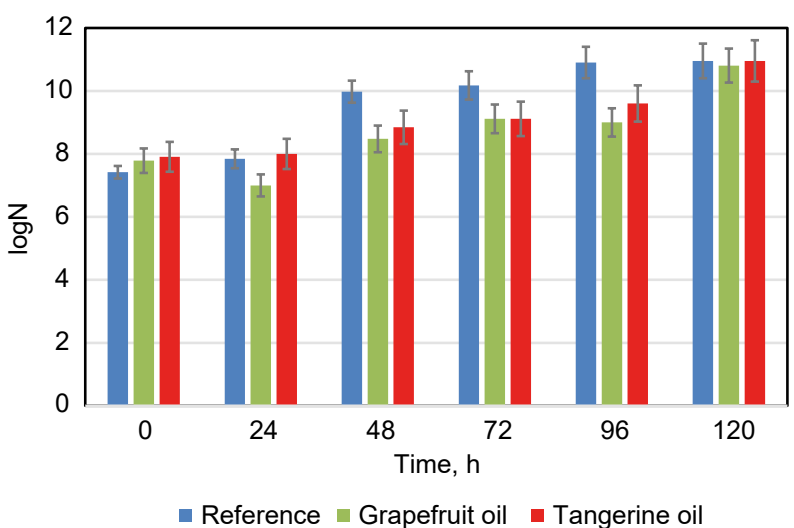

Fig. 1c. Changes in viable cells concentration during fermentation. $\log N$ on $Y$ axis is $\log _{10} N$, where $N$ is the number of viable $S$. boulardii cells, cfu $/ \mathrm{cm}^{3}$

inhibition resulted in a decrease in the number of viable cells in the beverages with essential oils by about one order in the first 48 hours, which affected the fermentation rate thereafter.

At the end of the fermentation, the apparent degree of fermentation was about $20 \%, 11 \%$, and $9 \%$ for the reference sample, the beverage with grapefruit essential oil, and the beverage with tangerine essential oil, respectively. It corresponded to an alcohol content of $1.29 \%(\mathrm{v} / \mathrm{v}), 0.89 \%(\mathrm{v} / \mathrm{v})$, and $0.68 \%(\mathrm{v} / \mathrm{v})$, respectively (Fig. 1b). Therefore, unlike the reference sample, the drinks with essential oils can be classified as low alcohol beverages according to Brányik et al. (2012).

The concentration of viable cells in the reference sample increased to $9.10^{10} \mathrm{CFU} / \mathrm{cm}$ at the end of fermentation. In the variants with essential oils, the initial decrease in viable yeast cell concentration during the first 48 hours was overcome and at the end of the fermentation the number of viable cells was similar to that in the control variant (Fig. 1c). The data in Figure $1 \mathrm{~b}$ and Figure 1c show that the essential oils affected the release of ethanol from the cells into the medium, most likely by inhibiting ethanol transport systems. It was observed that essential oils like allspice, cinnamon, clove, garlic, onion, oregano, savory, and thyme reduced the fermentation activity of Sacchraromyces cerevisiae (Conner et al., 1984).

It is noteworthy that the essential oils acted as defoamers, because in the reference sample the release of $\mathrm{CO}_{2}$ was visible when the sample was opened, but in the variants with essential oils, the amount of released $\mathrm{CO}_{2}$ seemed lower.

\section{Biological value}

It is known that essential oils add a certain biological value to beverages. All the beverages produced were firstly evaluated in terms of total phenols and then their antioxidant activities were compared. The results for total phenolic compounds measured using the FC method (Fig. 2a) showed approximately 1.5 times increase during the first 24 hours for the reference sample. This can be explained with the fact that yeast cells produce ferulic acid esterase, which leads to an increase in the accumulation of ferulic acid. At the end of the fermentation the results were almost equal to those at the beginning of the fermentation. According to Szwajgier

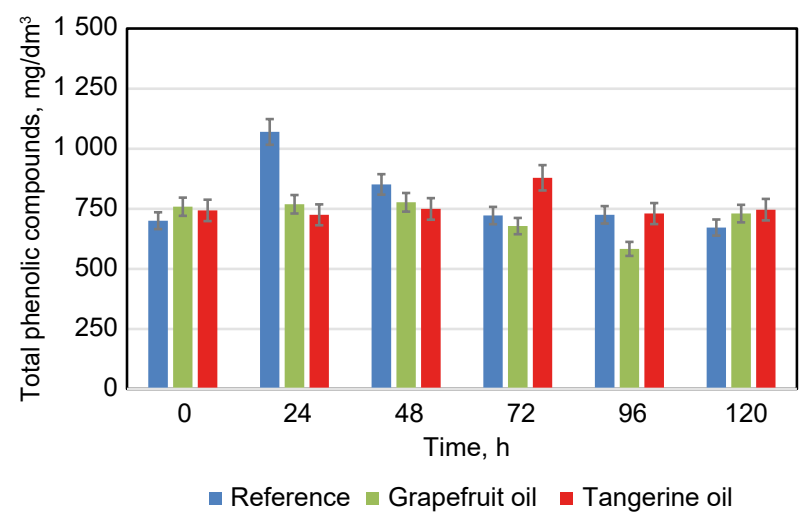

Fig. 2a. Changes in total phenolic compounds, measured using the FC method 
(2009), this might be due to the precipitation of tannins and non-tannin phenolics from wort and the absorption by yeast during fermentation. The peak of total phenolics for the beverage with tangerine essential oil was at the $72^{\text {nd }}$ hour, but such a peak was not observed for the beverage with grapefruit essential oil (Fig. 2a). At the end of the fermentation the level of total phenolics was higher in the beverages with essential oil.

The results for the concentration of total phenolic compounds, phenolic acids and flavonoid phenolic compounds are presented in Figure 2b, 2c and $2 \mathrm{~d}$, respectively. In general, the dynamics of the total phenolic compounds, measured using the modified Glories method (Fig. 2b) did not differ from those determined using the FC method (Fig. 2a). It is

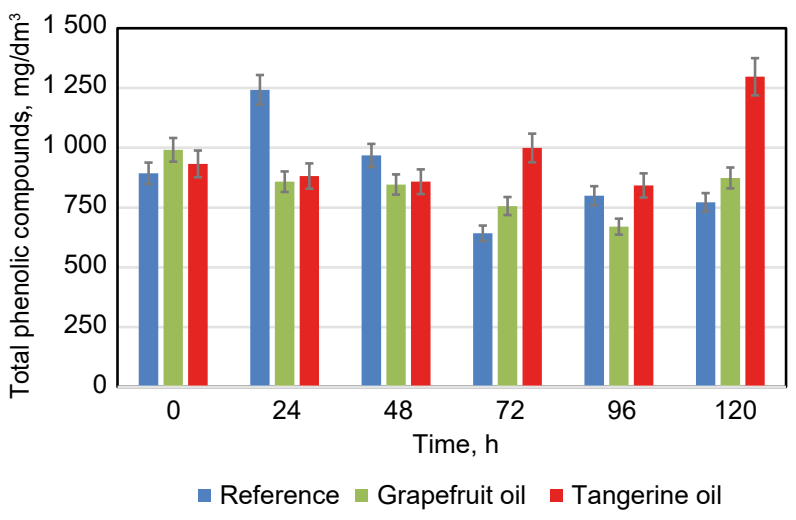

Fig. 2b. Changes in total phenolic compounds, measured using the modified Glories method

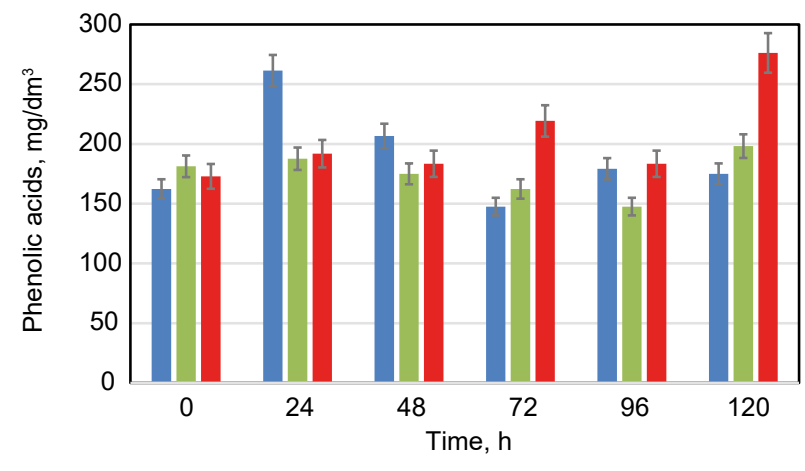

- Reference $\backsim$ Grapefruit oil $\|$ Tangerine oil

Fig. 2c. Changes in phenolic acids, measured using the modified Glories method

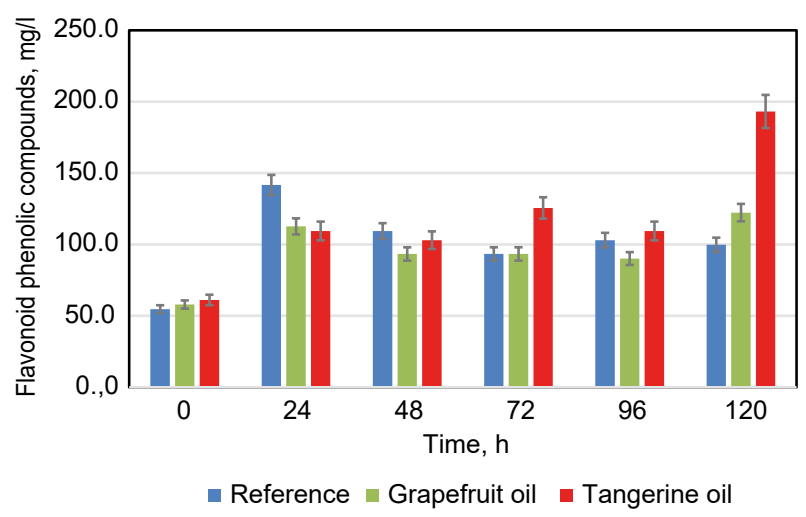

Fig. 2d. Changes in flavonoid phenolic compounds, measured using the modified Glories method

noteworthy that at the end of the fermentation the beverage with tangerine essential oil showed the highest concentration of total phenolic compounds. In the case of phenolic acids (Fig. 2c), the dynamic was the same as for total phenolics. Flavonoid phenolic compounds increased almost 2 times for the reference sample and the beverage with grapefruit essential oil and approximately 3 times for the one with tangerine essential oil. This was probably due to the fact that unlike phenolic acids, which are more reactive, flavonoid phenolic compounds remained in the wort and determined its antioxidant potential.

The antioxidant capacity of the beverages was analysed using the FRAP and DPPH techniques. FRAP evaluates the ability to reduce the Fe(III) complex to Fe(II) (Benzie and Strain, 1996), whereas DPPH assesses the reduction by antioxidants of free radical $\mathrm{DPPH}^{-}+$(Mishra et al., 2012). The results regarding the antioxidant potential of all the samples analysed through different methods are shown in Figure 3a and $3 \mathrm{~b}$. The DPPH assay showed that the addition of essential oils did not affect wort antioxidant activity. The antioxidant capacity decreased by about 500 $\mu$ mol TROLOX $/ \mathrm{dm}^{3}$ for the variants with essential oils and by about $100 \mu \mathrm{mol}$ TROLOX $/ \mathrm{dm}^{3}$ for the reference sample at the beginning of the fermentation process. However, at the end of the fermentation (Fig. 3a) no significant differences were observed in the antioxidant activities of all the samples. The FRAP assay showed an increase in the antioxidant activity of $100 \mu \mathrm{mol}$ TROLOX $/ \mathrm{dm}^{3}$ when essential oils were added (Fig. 3b). The dynamics in the antioxidant 


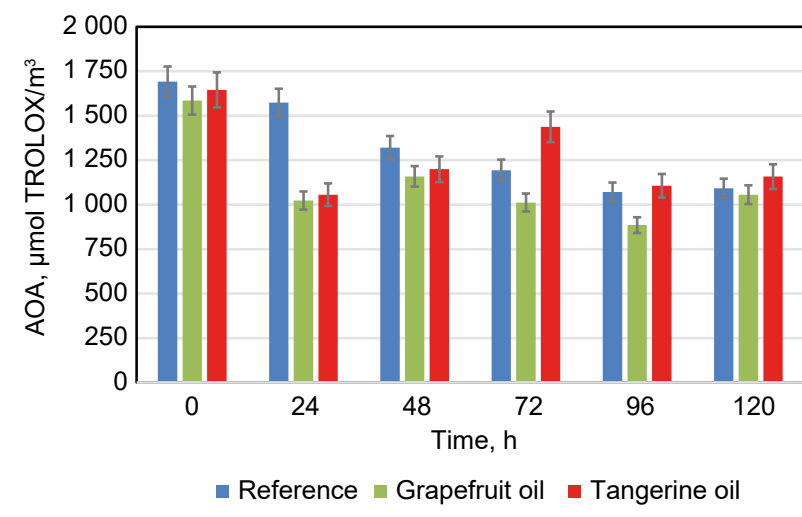

Fig. 3a. Changes in antioxidant activity, measured using the DPPH method

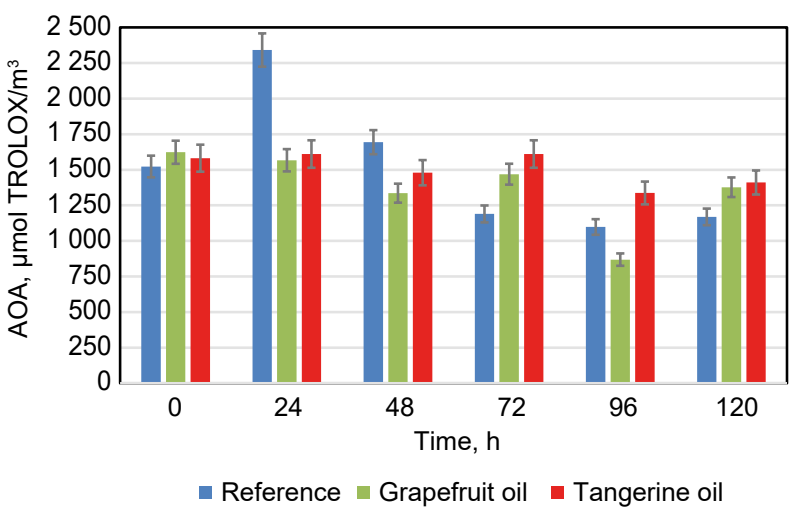

Fig. 3b. Changes in antioxidant activity, measured using the FRAP method

activity were different than the ones measured using the DPPH method. First, the reference sample antioxidant activity increased by approximately $500 \mu \mathrm{mol}$ TROLOX/ $\mathrm{dm}^{3}$ in the first 24 hours, which corresponded to the data for the phenolic compounds. At the end of the fermentation the antioxidant activity decreased by $1000 \mu \mathrm{mol}$ TROLOX $/ \mathrm{dm}^{3}$. In the variants with essential oils, the antioxidant activity was almost constant until the $72^{\text {nd }}$ hour and afterwards it started to decrease. At the end of the fermentation, the reference sample antioxidant activity was lowest. The differences between the results obtained using the two methods for evaluation of the antioxidant activity were based on distinct reaction mechanisms and take into account different proportions of the multiple substances with antioxidant properties in the beverages produced.
Despite the observed differences, one can assume that the reduction of the antioxidant activity was associated mainly with the loss of phenolic compounds.

As the fermentation process was carried out dynamically, multiple comparisons were made between the indicators determining the biological value of the beverages (antioxidant capacity and phenolic compound content). The results of multiple comparisons against the factor "Fermentation Time" performed using Fisher's least significant difference (LSD) method are presented in Tables 1a and 1b (data are presented only where statistically significant differences are found).

Table 1a. Multiple Range Tests - Method: $95.0 \%$ LSD

\begin{tabular}{|c|c|c|c|}
\hline & Count & Mean & Homogeneous groups \\
\hline \multicolumn{4}{|c|}{ DPPH } \\
\hline Grapefruit oil & 5 & 1027.19 & $\mathrm{X}$ \\
\hline Tangerine oil & 5 & 1191.48 & $\mathrm{XX}$ \\
\hline Reference & 5 & 1250.03 & $\mathrm{X}$ \\
\hline \multicolumn{4}{|c|}{ FRAP } \\
\hline Grapefruit oil & 5 & 1323.33 & $\mathrm{X}$ \\
\hline Tangerine oil & 5 & 1489.45 & $\mathrm{X}$ \\
\hline Reference & 5 & 1498.19 & $\mathrm{X}$ \\
\hline \multicolumn{4}{|c|}{ TPC (by FC) } \\
\hline Grapefruit oil & 5 & 707.246 & $\mathrm{X}$ \\
\hline Tangerine oil & 5 & 765.818 & $\mathrm{X}$ \\
\hline Reference & 5 & 807.856 & $\mathrm{X}$ \\
\hline \multicolumn{4}{|c|}{ TPC (by Glorie) } \\
\hline Grapefruit oil & 5 & 801.002 & $X$ \\
\hline Tangerine oil & 5 & 884.864 & $\mathrm{X}$ \\
\hline Reference & 5 & 975.78 & $\mathrm{X}$ \\
\hline \multicolumn{4}{|c|}{ PA (by Glorie) } \\
\hline Grapefruit oil & 5 & 174.146 & $\mathrm{X}$ \\
\hline Tangerine oil & 5 & 193.964 & $\mathrm{X}$ \\
\hline Reference & 5 & 210.83 & $\mathrm{X}$ \\
\hline \multicolumn{4}{|c|}{ FPC (by Glorie) } \\
\hline Grapefruit oil & 5 & 7.082 & 35.1558 \\
\hline Tangerine oil & 5 & -18.674 & 35.1558 \\
\hline Reference & 5 & -25.756 & 35.1558 \\
\hline
\end{tabular}


Tomova, T., Petelkov, I., Shopska, V., Denkova-Kostova, R., Kostov, G., Denkova, Z. (2021). Production of probiotic wort-based beverages with grapefruit (Citrus paradisi L.) or tangerine (Citrus reticulata L.) zest essential oil addition. Acta Sci. Pol. Technol. Aliment., 20(2), 237-245. http://dx.doi.org/10.17306/J.AFS.2021.0902

Table 1b. Contrast within the groups

\begin{tabular}{ccrc}
\hline Contrast & $\begin{array}{c}\text { Signifi- } \\
\text { cance }\end{array}$ & Difference & + +- Limits \\
\hline Reference - Grapefruit oil & $*$ & 222.846 & 216.324 \\
Reference - Tangerine oil & & 58.554 & 216.324 \\
Grapefruit - Tangerine oil & & -164.292 & 216.324 \\
\hline
\end{tabular}

*Denotes a statistically significant difference.

Table 1a applies a multiple comparison procedure to determine which means are significantly different from which others. The bottom half of the output (Table 1b) shows the estimated difference between each pair of means. An asterisk has been placed next to 1 pair (only for DPPH), indicating that this pair shows a statistically significant difference at the $95.0 \%$ confidence level. The homogenous groups are identified using columns of $X$ 's (Table 1b). Within each column, the levels containing $X$ 's form a group of means within which there are no statistically significant differences. The method currently being used to discriminate among the means is Fisher's least significant difference (LSD) procedure. With this method, there is a $5.0 \%$ risk of calling each pair of means significantly different when the actual difference equals 0 .

The data in Tables $1 \mathrm{a}$ and $1 \mathrm{~b}$ show that a statistically significant difference was observed only for the results of DPPH between the reference sample and the grapefruit oil sample. In the other indicators, no statistically significant differences were observed between the reference sample and the essential oil samples. Nevertheless, the results in Figure 2 are quite different in terms of the dynamics of the individual indicators, although this is not confirmed by statistical analysis. The most likely explanation is that during fermentation changes in the concentration of individual phenolic compounds occur, and statistically significant differences can probably be observed there.

\section{Sensorial evaluations}

At the end of the fermentation process, an organoleptic evaluation of the drinks obtained by a descriptive method was made (Table 2). This method was applied in order to evaluate the main characteristics of the beverages without ranking the samples due to their small volume. The reference sample showed some untypical flavours
Table 2. Results of descriptive sensorial analysis of beverage produced

\begin{tabular}{cl}
\hline \multicolumn{1}{c}{ Sample } & \multicolumn{1}{c}{ Description } \\
\hline Reference & $\begin{array}{l}\text { aroma: wort / sweet corn / toasted bread crust } \\
\text { taste: wort / caramel / honey }\end{array}$ \\
Grapefruit oil & $\begin{array}{l}\text { aroma: dried herbs / lavender / lemon peel } \\
\text { taste: harmonious taste / hints of lemon and } \\
\text { grapefruit }\end{array}$ \\
Tangerine oil & $\begin{array}{l}\text { aroma: faint aroma of tangerine } \\
\text { taste: fresh and harmonious taste / hints of } \\
\text { tangerine }\end{array}$ \\
\hline
\end{tabular}

like sweet corn, which can be ascribed to the yeast metabolism or to the malt used (Russell, 2018). Because in the other variants this flavor was not observed, it can be assumed that it was masked by the essential oils. The panel preferred beverages with tangerine essential oil because its taste and aroma were more typical and harmonious than those of the beverage with grapefruit essential oil. It was difficult to make a more detailed sensorial evaluation of the variants studied as no such beverages are available on the market yet.

\section{CONCLUSION}

A fermentation process with a probiotic strain Saccharomyces cerevisiae var. boulardii $\mathrm{Y} 1$ and tangerine or grapefruit essential oils was carried out to obtain a lowalcohol wort-based functional drink. The addition of essential oils led to lower alcohol concentration compared to the reference sample. Nevertheless, at the end of the fermentation the concentration of viable cells was higher than $10^{10} \mathrm{CFU} / \mathrm{cm}^{3}$ in all the beverages, which is a prerequisite for their functionality. The combination of essential oil and the probiotic yeast strain resulted in beverages with higher biological value than the beverages produced with the probiotic strain alone. The highest antioxidant activity and the panel's preference for the beverage with tangerine essential oil make it a subject of further study for process optimization.

\section{REFERENCES}

Analytica EBC (2005). Section 8 Wort 8.3 Extract of wort. Section 9 Beer 9.4 Original, real and apparent extract and original gravity of beer. Section 9 Beer 9.5 Fermentation 
Tomova, T., Petelkov, I., Shopska, V., Denkova-Kostova, R., Kostov, G., Denkova, Z. (2021). Production of probiotic wort-based beverages with grapefruit (Citrus paradisi L.) or tangerine (Citrus reticulata L.) zest essential oil addition. Acta Sci. Pol. Technol. Aliment., 20(2), 237-245. http://dx.doi.org/10.17306/J.AFS.2021.0902

degree. Section 9 Beer 9.2.1 Alcohol in beer by distillation. Nürnberg, Germany: Fachverlag Hans Carl.

AOAC (2007). Official method 934.06 for moisture in dried fruits. Gaithersburg, MD, USA: AOAC International.

Balinova, A., Dyakov, G. (1974) Improved apparatus for microdestilation of rose flower. Agric Sci., 11, 79-85.

Bamforth, C. W. (2004) Beer health and nutrition. Oxford, UK: Blackwell Science.

Briggs, D., Boulton, C., Brookes, P., Stevens, R. (2004). Brewing science and practice. Cambridge, England: Woodhead.

Brányik, T., Silva, D. P., Baszczyňski, M., Lehnert, R., Almeida e Silva, J. B. (2012). A review of methods of low alcohol and alcohol-free beer production. J. Food Eng., 108, 493-506. https//doi.org/10.1016/j.jfoodeng.2011.09.020

Benzie, I. F. F., Strain, J. J. (1996). Ferric reducing ability of plasma (FRAP) as a measure of "antioxidant power": The FRAP assay. Anal. Biochem., 239, 70-76. https// doi.org/10.1006/abio.1996.0292

Conner, D. E., Beuchat, L. R., Worthington, R. E., Hitchcock, H. L. (1984). Effects of essential oils and oleoresins of plants on ethanol production, respiration and sporulation of yeasts. Int. J. Food Microbiol., 1 (2), 63-74. https://doi.org/10.1016/0168-1605(84)90009-6

Czerucka, D., Dahan, S., Mograbi, B., Rossi, B., Rampal, P. (2000). Saccharomyces boulardii preserves the barrier function and modulates the signal transduction pathway induced in enteropathogenic Escherichia coli-infected T84 cells. Infect. Immunol., 68, 5998-6004. https://doi. org/10.1128/IAI.68.10.5998-6004.2000

Czerucka, D., Piche, T., Rampal, P. (2007). Review article: yeast as probiotics - Saccharomyces boulardii. Alim. Pharm. Ther., 26, 767-778. https://doi.org/10.1111/ j.1365-2036.2007.03442.x

Dinkova, R., Heffels, P., Shikov, V., Weber, F., Schieber, A., Mihalev, K. (2014). Effect of enzyme assisted extraction on the chilled storage stability of bilberry (Vaccinium myrtillus L.) anthocyanins in skin extracts and freshly pressed juices. Food Res. Int., 65, 35-41. https://doi. org/10.1016/j.foodres.2014.05.066

Dvořáková, M., Guido, L. F., Dostálek, P., Skulilová, Z., Moreira, M. M., Barros, A. A. (2008). Antioxidant properties of free, soluble ester and insoluble-bound phenolic compounds in different barley varieties and corresponding malts. J. Inst. Brew., 114, 27-33. https:// doi.org/10.1002/j.2050-0416.2008.tb00302.x

Fayed, S. (2009). Antioxidant and anticancer activities of Citrus reticulate (Petitgrain Mandarin) and Pelargonium graveolens (Geranium) essential oils. Res. J. Agric. Biol. Sci., 5, 740-747.
Haifeng, Z. (2014). Endogenous antioxidants and antioxidant activities of beers. In V. Preedy (Ed.), Processing and impact on antioxidants in beverages (pp. 15-24). Oxford, UK: Elsevier.

Mandal, S., Mandal, M. (2016). Tangerine (Citrus reticulata L. var.) oils. In V. Preedy (Ed.), Essential oils in food preservation flavor and safety (pp. 803-811). New York, USA: Academic Press. https://doi.org/10.1016/B978-012-416641-7.00091-2

Mazza, G., Fukumoto, L., Delaquis, P., Girard, B., Ewert, B. (1999). Anthocyanins, phenolics, and color of Cabernet Franc, Merlot, and Pinot Noir wines from British Columbia. J. Agric. Food Chem., 47, 4009-4017. https:// doi.org/10.1021/jf990449f

Mishra, K., Ojha, H., Chaudhury, N. K. (2012). Estimation of antiradical properties of antioxidants using DPPH assay: A critical review and results. Food Chem., 130, 10361043. https://doi.org/10.1016/j.foodchem.2011.07.127

Ng, T. B., Bekhit, E. D. A., Fang, E. F., Li, X., Lu, Q., Guo, H., Wong, J. H. (2016). Grapefruit (Citrus paradisii) oils. In V. Preedy (Ed.), Essential oils in food preservation flavor and safety (pp. 463-470). New York, USA: Academic Press. https://doi.org/10.1016/B978-0-12416641-7.00052-3

Niva, M. (2007). All foods affect health: Understandings of functional foods and healthy eating among health-oriented. Finns Appetite, 48, 384-393. https://doi.org/10. 1016/j.appet.2006.10.006

Regulation (EC) no 1924/2006 of the European Parliament and of the Council of 20 December 2006 on nutrition and health claims made on foods (2006). OJ L 404, 30.12.2006, 9-25.

Roberfroid, M. B. (2000). Concepts and strategy of functional food science: the European perspective. Am. J. Clin. Nutr., 71 (6 Suppl.), 1660S-4S, discussion 1674S-5S.

Russell, I. (2018). Yeast. In G. G. Stewart, I. Russell, A. Anstruther (Eds.), Handbook of brewing (3rd ed., pp. 225-274). CRC Press.

Senkarcinova, B., Graça Dias, I. A., Nespor, J., Branyik, T. (2019). Probiotic alcohol-free beer made with Saccharomyces cerevisiae var. boulardii. LWT, 100, 362-367. https://doi.org/10.1016/j.lwt.2018.10.082

Szwajgier, D. (2009). Content of individual phenolic acids in worts and beers and their possible contribution to the antiradical activity of beer. J. Inst. Brew., 115, 243-252. https://doi.org/10.1002/j.2050-0416.2009.tb00376.x

Turek, C., Stintzing, F. C. (2013). Stability of essential oils: a review. Compr. Rev. Food Sci. Food Saf., 12, 40-53. https://doi.org/10.1111/1541-4337.12006 
